\title{
Overcoming Male infertility through assisted reproductive technology : An Ethical analysis
}

\author{
Sharmin', Ruslin $B N^{2}$, Hanapi $B M N^{3}$, B Rani ${ }^{4}$
}

\begin{abstract}
This paper aims to address ethical issues related to the assisted reproductive technology of artificial insemination [AI] from the Western ethical perspective. Our evaluation suggests that Western ethicists offer some arguments both for and against the application of this modern assisted reproductive technology.
\end{abstract}

Key words: artificial insemination, assisted reproductive technology, Western philosophy, ethics.

The desire to have one's own offspring is a very strong human instinct. A heterosexual couple decides whether to have a child or otherwise. If their decision is positive, they could proceed to conceive a child by means of sexual intercourse. But some couples fail to become parents because of some medical reasons. The problem of infertility is as old as recorded history. Irrespective of religion, place, community, culture and time, people facing this problem have tried hard to overcome it.

Male infertility involves the following features: (a) inability to produce any sperm at all (azoospermia); (b) the number of sperms produced is too low to make impregnation of the female likely (oligospermia); (c) adequate numbers of sperm cells are produced but dysfunctional. This means that the sperms are not sufficiently motile to make their way past the vaginal canal and through the Fallopian tubes. As a result, their chances of reaching and penetrating an ovum are diminished; (d) neurological conditions that make ejaculation impossible; and (e) impotency due to diseases such as diabetes mellitus. 1 In these circumstances, Artificial insemination[AI] can help the male partner overcome childlessness.

Artificial Insemination (AI) is a technique in which the sperm is placed in the female reproductive tract by mechanical methods that precludes sexual ejaculation into the woman's vagina .2

Therefore, three points can be derived regarding AI based

\begin{tabular}{l}
${ }^{1}$ Associate Professor, Northern University Bangladesh. \\
${ }^{2}$ Ex Deputy Dean, School of Dental Sciences [PPSG], Universiti \\
Sains Malaysia [USM]. \\
${ }^{3}$ Ex Director, Islamic Center [Pusat Islam], Universiti Sains \\
Malaysia, Health Campus, Kota Bharu, Malaysia. \\
${ }^{4}$ Ex Dean, School of Dental Sciences[PPSG], Universiti Sains \\
Malaysia [USM]. \\
\hline Address of correspondence: Dr. Sharmin Islam \\
Associate Professor, Northern University Road \# 4/A, House: 54, \\
Dhanmondi R/A. \\
Email:Sharmin320@hotmail.com
\end{tabular}

${ }^{2}$ Ex Deputy Dean, School of Dental Sciences [PPSG], Universiti Sains Malaysia [USM].

Ex Director, Islamic Center [Pusat Islam], Universiti Sains . Kota Bharu, Malaysia.

Ex Dean, School of Dental Sciences[PPSG], Universiti Sain

Address of correspondence: Dr. Sharmin Islam

Dhanmondi R/A

Bangladesh Journal of Medical Education 2014;5(1):10-14. C 2014 Sharmin et al., publisher and licensee Association for Medical Education. This is an Open Access article which permits unrestricted non-commercial use, provided the original work is properly cited. offers certain potential psychological benefits over the alternative of adoption. Because both husband and wife can be involved in the pregnancy from conception onward, sharing the experience of delivery and the early days of the baby's life. There is a chance that the child's physical appearance will at least match that of the mother. Furthermore, if there are several children they are more likely to resemble one another. Any subconscious fear of the sudden appearance of the natural mother is nil as there may on the above definition: (a) $\mathrm{AI}$ is a technique in which sperm is placed in the female reproductive tract by mechanical methods rather than sexual intercourse; (b) The man does not ejaculate into the woman's vagina; and (c) The sperm has to be placed into the female reproductive tract with an instrument.

There are two types of AI depending on the source of the sperms employed in the procedure: Artificial Insemination Homologous (AIH) and Artificial Insemination Heterologous/ Donor (AID). In AIH, the sperm is collected from the male partner. The name of the process is commonly abbreviated as AIH and the ' $\mathrm{H}$ ' frequently refers to the 'husband'. However, the male partner does not necessarily denote the legal husband. That is, a legal marriage bond is not a strict requirement in this procedure. Rather, the male partner needs only be the functional equivalent of a husband. 1

Before undertaking $\mathrm{AIH}$, the semen has to be certified normal and that it does not and cannot enter the cervical canal in the usual way. 3 Those are just one set of criteria. Nowadays, AIH is carried out even in cases of poor quality semen.

AID uses sperms from a donor other than the 'husband'. It is employed when the problem is an irreversible sterility of the 'husband.' AID is recommended when the male is unable to produce any sperm at all (a condition called 'anospermia'), or the number of sperm he produces

may be too low to make impregnation of the female likely (a condition known as 'oligospermia'). Even in spite of sufficient number of sperm cells produced by the husband, they may not function normally. They may lack sufficient motility to make their way past the vaginal canal and through the opening to the uterus. When the husband suffers from a neurological condition that makes ejaculation impossible or from a disease such as diabetes, he may be impotent.1

In the Western secular philosophical context, ethical judgment about the use of AID is two fold. It is both positive and negative in ethical measurement. It is argued that AID 
be in adoption. And, of course, the desire on the part of the mother to carry a child is satisfied in contrast to adoption. 4

However, there is a problem. The mother may be guilty of committing adultery because of taking donor sperms whether or not this feeling is justified in the forum of conscience. In our ordinary lives, customary morality is often more powerful than rational morality. In fact, it is especially true in primitive personalities however sophisticated or cultured they are. 5 The wife may have felt 'cheated' by discovering the sterility of her mate. The desire to procreate despite this discovery may become, in part, an act of revenge toward the barren husband. 6 If AID is successful, the wife may have a complex feeling that the new life she bears within her has no relation to the love she has for her husband. 7 The situation would be to some extent complex if she secretly yearns to meet the man who 'helped' her when the husband could not. 4

The psychological threat of the husband is perhaps greater than the wife. Man's sense of ego is stronger than that of a female. When he discovers that he is unable to impregnate his wife, he suffers from an inferiority complex. It is a threat to his masculinity. Attempting AID may make the situation more difficult. He may have a sense of jealousy towards the donor because of his inability to procreate. "AID, thus, threatens to evoke very deep-seated feelings of helpless dependence in relationship to women and also feelings of inadequacy in relation to other men" . 6 The husband may psychologically withdraw from the home, engaging him in his work or other forms of self-achievement by which he may hope to regain his sense of masculinity. 6 Sometimes, in order to overcome this type of problem, doctors often ask the husband to press the plunger of the syringe so that he will have a feeling that he himself has made his wife pregnant. But it is doubtful whether this act would improve the complex situation.

These psychological dangers for husband and wife also hamper the psychological development of the child. They pine for knowledge of, and connection to, the missing halves of their very selves. Somebody born out of donor sperm expressed his emotional thirst in this way: "We don't want money. ... We have the fundamental questions that everyone has growing up. Where did I come from? Who am I? Do I have their eyes, their nose, their hair" ? 8 "People don't realize how painful this is," says Cordray, now 48. "I feel a part of me is not complete. I want to know what (my biological father's) family is like. I want to know where I came from." 9 Consider the case of Bary Stevens. He at the age of 18 with the death of his "adoptive" father came to know that he was born through AID which had been done at a private clinic of Mary Barton and Berthold Wiesner in London, U.K. But we find Stevens here that even in his late 40 s he sets out to uncover his missing genetic heritage. 10

An important ethical issue is associated with the question: what would be the correct approach regarding whether to disclose or not to disclose the fact about the identity of the child? Some would offer argument in favor of disclosing his/her true genealogy to the child. According to them, the risk of accidental disclosure may cause parents to decide that forthrightly telling the child at an appropriate age would contribute to a healthier relationship. There is no parallel to truthfulness in life. Disclosure is necessary because knowledge of one's genealogical heritage may be crucial if the child suffers any genetic illness or needs a reliable family medical history. If not disclosed, AID makes way for marriage between half-siblings. The semen from the same donor is often used with women who live in the same geographic community and who may represent a rather homogeneous ethnic or social group. The dangerous thing is that AID children of the same donor would have marital relationship. 4

Man makes society and the welfare of society seriously hampered if the ideal of truth-telling is not practiced there. G.D Mitchell highlights on this point by saying that secrecy over donations of semen or embryos attacks the whole practice of truth-telling on which society and our dailycommerce with one another depends. To quote him, "why receiving donated sperms and oocytes are deleterious to society. Firstly, a donation is frequently shrouded in secrecy and of a kind that leads members of families to be deceitful. Secondly, it gives rise to births of children who are denied adequate, or at least normal, knowledge of their genetic origins". 11

Actually, secrecy and deceit are not essential concomitants of sperm and oocyte donation. There must be pure frankness and free information about the entire transaction. It is to mention that isolated and particular instances in which people are less than frank with one another do not threaten society. He speaks about a society in which children can never trust what they are told about their origins because the mere existence of artificial insemination and oocyte donation which are sometimes undeclared means that children in normal families can never be sure of any answer they are given. Mitchell's second worry is that it cannot be right to support processes which may well lead to the creation of children suffering some kind of deprivation which children born in the usual way may not expect to endure. According to Mitchell, "This is knowledge which helps a child acquire an identity; he knows where he belongs. Not to have this knowledge may be said to deprive him of a natural right. So should we, as a society, and the profession of medicine in particular, connive at producing children who begin life with a disadvantage". 11

Every man wants to know his real origin, his root. The argument for the disclosure of AID seems very strong here. But it is not absolutely true. As an infertility specialist Dr. Richard Casey opines that it is difficult finding donors even with assurances their identities will be safeguarded. 9 To quote him, "It would be virtually impossible if they knew that at a future date they may have some people knocking at their door, saying, 'You're my dad, and I wanted to see you'. The primary concern is the donor, who is making the whole thing work". 9

Bangladesh Journal of Medical Education 2014;5(1):10-14. 
Whether to reveal or not to reveal the secret of AID can be a serious concern for the husband. Consider the case of Mr. L, a handsome man of late 30 . He is university educated and holds a good job. He is married to a highly educated woman. His quandary over whether to keep the secret or reveal it and if so, when and how, causes a serious emotional disturbance and makes his life very unsettle and haphazard. The preoccupation with the secret and the question regarding its concealment or disclosure constitutes an organizing and containing envelope for other concealed issues and unconscious conflicts seeking revelation: who am I and where did I come from? Unsatisfactory answers to these cardinal questions during the pre-oedipal and oedipal stages of development can create a complex dilemma to overcome. 12

Ethical question also arises regarding the status of the child born through AID. It may be a striking question: as the involvement of a third party is evident, whether the child would be illegitimate or not. Against such a possibility, it is claimed by a Western bioethicist that marriage bond is not a strict monopoly on totalitarian ground. AID is surely not adultery if marriage fidelity is conceived to be personal rather than a merely legal relationship. It is feasible in two ways. Firstly, artificial insemination mutually agreed upon by husband and wife does not involve any broken faith between them. Secondly, no personal relationship is entered into with the donor at all. So the charge that AID is adultery is a legalism, not a personal or moral objection at all. Interpreted in this way, AID would acquire a new dimension of thought. 5 Fletcher emphasizes on the 'personal' character of the marriage bond rather than on any notion of a physical bond. He is unfettered by concepts of the rightness or wrongness of given physical acts apart from the significance love assigns to them. Moreover, he exalts the superiority of the spiritual over the physical in the scope for alternative offered through the technology of AID. He, therefore, welcomes this choice when it is the result of mutual trust and agreement between husband and wife. Helmut Thielicke argues on another line. He says that the introduction of donor semen violates the mysterium of marital fellowship and the psychophysical unity of husband and wife. This violation also manifests itself when the fulfillment of motherhood which is not accompanied by the fulfillment of fatherhood, breaks down the personal solidarity of the married couple. 13

Bioethicist Dr. Nigel Camer speaks about donor sperms in terms of human dignity and honor. He refers to the wellknown book in Bioethics world If I Were a Rich Man, Could I Buy a Pancreas? and strictly argues against sperm donation. According to him, things are bought and sold, but persons should not be and human dignity prevents us from doing that kind of act. When we are involved into buying and selling body parts for the purpose of making babies, we are moving rapidly into the notion that children are chattel because we have designed them. Moreover, we have to go so far away from the context of sexual love and in this way, babies are made, not procreated.14 In fact, from the standpoint of ethics, our concern should be not only the correct end but also the correct means. In AID, the means separates the meaning of 'personal' and 'human' from physical, bodily processes. The love-making and life-giving dimensions of sexual intercourse of a valid married couple ultimately give the birth of a child. But in AID where the sperm is taken from a donor, the resultant child would not be the outcome of the loving sexual act between a husband and a wife. This is also the concern of Islamic ethics. Islamic ethics is also against AID as it involves participation of a foreign element in procreation other than the husband.

The AID children will have to face the complexity of law in inheritance and others. The relationship between the child and the mother asks no question. But if the mother is married when the child is born, the child may not be considered legitimate. In a small number of states, if the husband gives consent to AID, the child is called his legitimate child. 15 If he denies the child's legitimacy, he bears a heavy burden of proof that he did not consent. The sperm donor also has a chance to be entitled with fatherhood of the child. But, he is likely to be protected by anonymity in the records of the sperm bank. So, he is deprived of being the natural father. But the law tends to favor private sources of support for children. And for this reason, the child may receive support from the inseminator. Otherwise, the AID's child will have no natural father and hence fewer potential sources of support than has the illegitimate offspring. It still remains a question: should the husband's consent to the AID make any difference to the possible liability of the sperm donor for support. Like adoption, it is likely that the liability of the donor would cut off by the husband's consent to AID. Again, a question arises: who is to then bear the burden of proving that consent or non-consent in a case in which the kid not having any support from the mother's husband, seeks support from the donor. 15 Islamic ethics does not have to handle this type of problem because it does not pave the way for it at the beginning by forbidding the practice itself.

Different technologies that have been developed during the last few decades open the way for the possibility of posthumous reproduction. There are different ways of semen preservation. Now a days, Cryopreservation of semen is very common in the U.S.A and elsewhere. Some times, people store their sperm at a sperm bank if they are worried that their sperm may become damaged. They fear about being exposed to harmful chemicals at work or about getting a disease that would damage their sperm. But for the most part, sperm banks are used by people who are willing to donate sperm to be used in artificial insemination. The sperm bank will first find out about the medical and social background of the donor. If the person concerned passes this criterion the sperm bank will pay him a fee for his sperm. The sperm bank then gets in touch with doctors and other people who use techniques like artificial insemination. A doctor then uses the sperm to help an infertile woman to conceive and charges a fee from her. 2 Posthumous reproduction can be achieved even in cases where a man did not store semen during his lifetime. Current medical technology makes it

Bangladesh Journal of Medical Education 2014;5(1):10-14. 
possible for physicians to retrieve sperm from a deceased male within twenty-four hours of his death. 16 The wife of the deceased person can use the sperm of the dead husband for procreation. Question arises regarding its ethical validity.

Question of ethics comes regarding the status of the deceased person. Metaphysically a person disappears from his body at death but the dead body still continues to command respect. 17 Though people in some cultures believe that organs and physical structures of the once living are no longer important, Western society deals with the matter not so lightly. Nevertheless, this almost sacred respect for the deceased person is not held to be absolute. Most people in Western society support that there are some exceptions when the body may be disturbed before being

buried, for example, for postmortem examinations and for organ or tissue retrieval for transplantation. Still, many have a natural revulsion to the idea of cutting, opening and inspecting the dead body, the potential utilities to the medical profession, the family or to society as a whole have generally overcome this obstacle as long as the autopsy procedure is carried out with the maximum possible respect for the departed person. 18

There has been some aesthetic, cultural and religious resistance to the practice of organ retrieval and transplantation as an enterprise. Some people though accept organ transplantation, have some specific reservations about the disrespectful treatment of dead bodies in some circumstances. For instance, Frader has criticized the practice of providing artificial support for a pregnant corpse to bring the gestating fetus to viability, maintaining that this represents a profound disrespect for the dead body. 19

Actually, the act of posthumous conception raises a large number of complex ethical and social issues. The wellbeing of the child is a very crucial issue in this context. The decision to help a woman to conceive by using the sperm of her deceased partner, whether voluntarily frozen for that purpose before death or retrieved posthumously, should consider the welfare of the coming infant. This calculation is definitely tough and the conclusion may vary depending on the social circumstances and on personal values. But the key point is that the child's interest cannot be overlooked. 18 So Orr and Siegler have sketched out a restrictive outlook towards posthumous sperm retrieval which would limit insemination to those cases where the deceased man has provided explicit consent for such a procedure. As such this conservative view dominates current law and practice.

In contrast to Orr and Siegler, another view would permit insemination and conception in the cases in which posthumous conception has been totally refused or where there is no reasonable evidence that the dead man desired it. Parker explains the phenomenology of procreative desires which supports the permissible view and which is compatible with requirements concerning the interests of the decedents, concepts of medical infertility and the well- being of the coming offspring. 20 But how would Parker tackle the issue if one leaves property to one's children but has frozen sperm or embryos that might produce children decades after one's death, what would be the rule of distribution of property?

The new situation in Israel is inconsistent with the situation in the U.K. where the law allows a woman to use her sperm after his death only if he had given clear consent for its use before his death. It was the effect of this strict law that Diane Blood had to fight to use her dead husband's sperm to become pregnant. 21

In fact, there is difference regarding the acceptance of posthumous semen retrieval in Western secular philosophical mode of thought. Suspecting a bad future of the coming offspring Orr and Siegler offered a restrictive attitude towards posthumous semen retrieval for reproduction. They hypothetically defend it provided the deceased person had given consent. On the other hand Parker supported it categorically. Again, Hoffman and Morriss condemned this practice highlighting the problem in distribution of wealth. 22

\section{Conclusion}

Finally, in Western ethics, AIH even if it is practiced by a legal husband, some ethicists condemn it on some grounds. It seems unusual restriction in using modern assisted reproductive technology to overcome male infertility On the other hand, although Western societies have made AID easily accessible on the plea that procreative liberty is predominant there, kids are not seeking to be raised or supported by the donor fathers. They pine for knowledge of, andconnection to, the missing halves of their very selves. They are wasting time disputing with the issue of whether to disclose or not disclose the identities of sperm donors. In the name of procreative liberty, they are ultimately doing harm to society because they are making the family ties weak.

\section{References}

1. Munson, R. (1996) Reproductive Control: In Vitro Fertilization, Artificial Insemination and Surrogate Pregnancy. In: R. Munson,(ed). Intervention and Reflection: Basic Issues in Medical Ethics. 5th Ed. Stamford: Wadsworth:489-551.

2. Anonymous (a) (1999) Reproductive Technologies. In: SG Post,(ed). Bioethics for Students: How Do We Know What's Right? Issues in Medicine, Animal Rights and the Environment. Vol 1. New York: Macmillan Reference:177-99.

3. Teoh, ES. (1987) Infertility: Finding the Right Solution. Singapore: Times Books International.

4. Schneider, ED. (2006) Procreation Ethics Series: Artificial Insemination [Online]. [Accessed 13th October 2006]. Available from World Wide Web:http://www.elca.org/jle/alc_lca/alc_lca.procreati on_ethics_artificial_insemination.html.

Bangladesh Journal of Medical Education 2014;5(1):10-14. 
3. Fletcher, J. (1979) Morals and Medicine: The Moral Problems Of: The Patient's Right to Know the Truth, Contraception, Artificial Insemination, Sterilization, Euthanasia. Princeton: Princeton University Press.

6. Ostrom, K. (1971) Psychological Considerations in evaluating AID. Soundings. 54(3):293-96.

7. Haring, B. (1975) Ethics of Manipulation. New York: The Seabury Press.

8. Wolff, J. (2004) Sperm Donor Ruling could Open the Door for Offspring (Final Edition), USA Today, Mclean, VA, June 15: A13.

9. Anonymous (b) (1993) Brave New Womb. Ethical and Legal Issues Surrounding Reproductive Technologies. Chatelaine (English edition).66(8):30-38.

10. Murphy, G. (2002) Donor Insemination: Finding your Roots. The Lancet.

11. Mitchell, GD. (1983). In Vitro Fertilization: The Major Issues-A Comment. Journal of Medical Ethics.9(4):536-40.

12. Landau, G. (2003) To Reveal or Not to Reveal a Secret. American Journal of Psychotherapy. 57(1):122-37.

13. Doberstein, JW. (1964) The Ethics of Sex. New York: Harper \& Row.

14. Anonymous (c) (2006) Making BabiesInterview: Nigel Cameron [Online].[Accessed 13th October 2006]. Available from World Wide Web: www.pbs.org/wgbh/pages/frontline/shows/fertility/int erviews/Cameron.html.
15. Tuckler, D. (1977) Some Legal Problems of Fabricated Man. Proceedings of the Conference on Fabricated Man IV: Fabricated Man and the Law, The Institute for Theological Encounter with Science and Technology (ITEST), Fordyce House, Saint Louis, Missouri, October 7-9, 1977. [Online]. [Accessed 14th January 2006]. Available from World Wide Web: http://itest.slu.edu/dloads/70s/fabman6/fabman6.txt.

16. Kerr, SM et al.(1997) Postmortem Sperm Procurement. Journal of Urology. 157(6):2154-2158.

17. May, W. (1973) Attitudes toward the Newly Dead. Hastings Center Report.1(1):3-13.

18. Orr, RD \& Siegler, M. (2002) Is Posthumous Semen Retrieval Ethically Permissible? Journal of Medical Ethics. 28(5):299-302.

19. Frader JE. (1993) Have We Lost Our Senses? Problems with Maintaining Brain-dead Bodies Carrying Fetuses. Journal of Clinical Ethics. 4(4):347-48.

20. Parker, M. (2004) Response to Orr and SieglerCollective Intentionality and Procreative Desires: The Permissible View on Consent to Posthumous Conception. Journal of Medical Ethics. 30(4):389-392.

21. Itzkovich, JS . (2003) Israel Allows Removal of Sperm from Dead Men at Wives' Request. British Medical Journal (International Edition).327(7425):1187.

22. Hoffman, S and Morriss, AP. (2004) Birth After Death: Perpetuities \& the New

Bangladesh Journal of Medical Education 2014;5(1):10-14. 